\title{
Trainees and research
}

\author{
JACQUeline M. AtKInson, Senior Lecturer in Behavioural Science, Department of \\ Public Health, 2 Lilybank Gardens, Glasgow G12 8RZ; and DenISE A CoIA, \\ Consultant Psychiatrist, Florence Street Day Hospital, Florence Street, Glasgow G5
}

Over recent years there have been a number of articles in the Psychiatric Bulletin considering the vexed question of research and trainees in psychiatry, most recently the suggestion of 'research troikas' by Sims (1992). Although this might work well in teaching hospitals with a reasonable number of academic staff, we see problems for the more peripheral areas. This article addresses these problems particularly as they affect people working outside the main centres. We are not concerned here with what trainees need to know about research, but rather how conducting research fits into their clinical job. We will do this by posing a number of basic questions.

\section{Why are registrars and senior registrars expected to do research?}

The first answer is usually 'to get a job'. While this is true in many specialties and in centres of excellence, it is not true in all parts of the country or for all jobs in psychiatry (there may be little competition for some mental handicap and psychogeriatric posts). Without wishing to sound like a latter-day Gordon Gekko (he of Wall Street fame) it may be that one answer for lack of research is that trainees 'are not hungry enough'.

Although a central motivation for doing research should be to find something out, this may be more true for those who choose to follow an academic, research-orientated career. For individuals working alone, with little support, this may not be enough to sustain them in what can be an arduous task, and may only succeed where there are good role models. The importance of a mentor cannot be overestimated, although in some cases this person may have to be geographically distant.

Being famous as a result of research has a low probability of success and is most likely to come over time rather than as an instant reward. One possible way of increasing motivation is to remind registrars of the research option in the MRCPsych examination (Adams, 1992).

The problem of time to do research has been raised (Bartlett \& Drummond, 1992) and while this may be true for registrars, it should not be for senior registrars who, with two sessions a week, have more time than many academics. It should be the role of trainers to investigate if something is not produced in this time. With audit creeping into every part of our lives it may soon be a case of research time needing to prove its worth.

Part of the problem may concern attitude. It would be wrong to expect people to work longer and longer hours, but the notion of research as 'a hobby' for which time has to be carved out of other interesting activities tends to be one that sustains not only researcher/clinicians but academics of all persuasions.

Another aspect of the time problem may depend on the type of research trainees are trying to undertake.

\section{What counts as research?}

There appears to be a feeling among trainees that they need to be involved in a 'big' project to do with major clinical outcomes. This is likely to involve a number of other people over a considerable period of time and may, as Barlett \& Drummond (1992) ruefully pointed out, still not lead to the elusive publication - or not in time to be useful for the next job application. The telling phrase of theirs is, however: "The other option is to aim for a lesser publication in a reputable journal" (our italics).

Maybe some trainees are guilty of trying to run before they can walk. If publications are the main yardstick by which research activity and promotion are judged, then there are other options than 'big' research.

A good review of the literature precedes any piece of research, can be published and demonstrates understanding of research methodology, statistics and clinical relevance just as clearly as 'active research'. According to Junaid \& Daly (1991) this made up 63\% of trainees' publications, while of the trainees' contributions to original research $60 \%$ were case reports. Both of these are ways of getting published for the registrar with little time to collect original data or the senior registrar with little research inclination.

Surveys, audit and evaluation are other options. These may not be viewed as the most exciting forms of research, but they avoid the need to recruit potentially unattainable numbers of patients. Surveys are usually largely descriptive and need not require elaborate statistics. Although some people do not see audit as research it still requires the following of a 
formal procedure, analysing the audit loop, which includes the setting of standards, measurement of achievement of standards and putting in place mechanisms to close the audit loop.

Audit, being currently popular, may have money available to support it. We have heard it suggested that people could even fund some small amounts themselves. While this raises a number of issues, it could be argued that paying some research expenses as part of career development and advancement is no different from paying fees for training analysis.

Working as part of a team can open up opportunities and experiences not available to an individual junior researcher. Sims (1992) suggested that trainees can carry out the 'leg work' of the research which, we agree, is an appropriate role for them, although many trainees do not see this as their role. This leads consultants to employ research assistants who may be more reliable and better motivated to fulfil this function in a given time period. Trainees are advised to clarify authorship of any publications before starting work, and ask about the time scale. Realistic publication dates may be too late for the trainee's next job application.

Collaborators need not be other trainees or consultants. Clinical psychologists, for example, are trained in research methods and statistics and may also want to increase their list of publications. Working together may not only make research more feasible but produce more papers as they can be slanted at the different professional groups. Being from different disciplines can also reduce the more unseemly aspects of competition.

\section{How do trainees learn about research?}

A number of centres run Masters courses for the most motivated, and many areas run research seminars/ courses as part of the day release programme. One way forward would be to have a single research tutor rather than individual consultants reluctantly supervising individual projects. The College runs courses for trainees and for consultants wishing to become tutors. It may be at that level that the particular problems of those outside academic centres need to be addressed. But this leads us to the major question:

\section{Does everyone need to do research?}

The role of research training has been discussed elsewhere. If everyone is expected to carry out research then, we would argue, this should play a greater part in the undergraduate training of doctors and become a formal part of the psychiatric trainee programme. Even for non-researchers, knowledge of methodology and design is necessary to understand the published work of others.

In a market where it is possible to obtain jobs without published research, maybe it would be better to accept that some people are not interested in pursuing research. This need not mean that they will not be good clinicians. Theoretical bias may also play a part since it has been suggested that those who are analytically orientated may be less interested in research than those following a biological or behavioural model (Toone et al, 1979).

\section{Conclusions}

There is no single solution to the problems trainees have in completing research. Solutions will almost certainly be different outside academic centres, and particularly the four main centres identified by Junaid \& Daly (1991). This leads us to suggest that (a) clarification is needed about the role and responsibilities of research supervisors, (b) that the role of the research tutor should be that of a coordinator for trainee's research but not necessarily to supervise all the research, (c) to do this properly research tutors require a session allocated specifically for this, and (d) a wider perspective needs to be taken on what counts as research and this should include audit.

\section{References}

ADAMs, S. (1992) The research option: educators' attitudes. Psychiatric Bulletin, 16, 418-420.

Bartlett, A. E. A. \& Drummond, L. M. (1992) The problem with registrar research. Psychiatric Bulletin, 16, 361-362.

JUNAID, O. \& DALY, R. (1991) An audit of research activity among trainee psychiatrists. Psychiatric Bulletin, 15, 353-354.

Sims, A. (1992) Research troikas: a plan for fostering psychiatric research in a region. Psychiatric Bulletin, 16, 605-607.

Toone, B. K., Murray, R. M., Clare, A., Creed F. \& SMIth, A. (1979) Psychiatrists' models of mental illness and their personal backgrounds. Psychological Medicine, 9, $165-178$.

A full list of references is available on request to the authors. 